Sādhanā Vol. 39, Part 6, December 2014, pp. 1409-1423. (C) Indian Academy of Sciences

\title{
Identifying the best market to sell: A cost function formulation
}

\author{
SUNIL KUMAR KOPPARAPU ${ }^{1, *}$ and VIKRAM SAXENA ${ }^{1}$ \\ ${ }^{1}$ TCS Innovation Labs, Tata Consultancy Services, Yantra Park, Thane (West), \\ Maharastra 400 601, India \\ e-mail: sunilkumar.kopparapu@tcs.com; vik.saxena@tcs.com
}

MS received 17 December 2013; revised 27 March 2014; accepted 24 August 2014

\begin{abstract}
One of the main objectives of a farmer is to sell his final agricultural produce so as to maximize his profits. While he has several options, in terms of the markets where he can sell his produce, he is faced with a dilemma of identifying a market where he should sell his produce. There are several factors, like (a) the distance of the market from the farmers location, (b) the type of produce, (c) the transportation cost, (d) the time taken to transport, that determine and influence the choice of market to sell. The main contributions of this paper include (a) the formulation of an optimization problem to identifying the best where and when to sell and (b) demonstrating the usefulness of the formulation on real world data.
\end{abstract}

Keywords. Optimization; commodity price; objective function.

\section{Introduction}

Science and Technology have always influenced the growth and advancements in all aspects of human advancement. Information and Communication Technology (ICT) is being increasingly used in agriculture to bring in science assisted methodologies to efficiently cultivate crops. There are several pockets of work being done towards this. For example, use of ICT has benefited the overall agriculture production by addressing different stages involved, namely, procurement of seeds, irrigation, cultivation, harvesting, storage, etc. For example, technology has been used effectively to give personalized advises to farmers on various aspects of cultivation (TCS 2013). However, the last mile of the cultivation process, namely selling the agricultural produce has not been addressed sufficiently. To the best of our knowledge, when it comes to assisting a farmer to sell his produce there is not much work reported except the availability of a real-time commodity prices data in different markets (Agmarknet 2013) or providing a voice user interface (VUI) to get real-time information of commodity rates (Imran \& Kopparapu 2011).

*For correspondence 
The farmer does have access to day-to-day information related to agricultural produce at various markets such as the minimum or maximum selling price of an agricultural produce, quantity traded, the variety of the agricultural produce. However, very often this information is not sufficient for a farmer to take a final decision as to in which market he should sell his agricultural produce so that he reaps the best profits because there are several parameters, operating in different directions, that determine the best where and when to sell market. Clearly, there is a need for a system which can assist a farmer not only decide the market where he should sell his produce but also tell him when he should sell his produce so that he can maximize his profits.

The main contributions of this paper are: (a) construction of a cost function to be able to identify the best market to sell and also when to sell, (b) the formulation of the problem to identify the best where and when to sell market as an optimization problem and (c) validation of the usefulness of the formulation on real dataset. This problem is an extension of Saxena \& Kopparapu (2013) where we had addressed only the aspect of where to sell. The rest of the paper is organized as follows. We give a brief survey of literature related to our work in section 2 . We construct a cost function and formulate the problem of identifying the best market to sell and when to sell as an optimization problem in section 3, we give some results in section 4 with real data and conclude in section 5.

\section{Literature survey}

While there is not much literature directly related how to identify the best place to sell a commodity to maximize profits, we review some of the related academic literature. It should be noted that almost all the work in this area is related to hedging, which unfortunately is not an option for the marginalized Indian farmer. As mentioned in Kaur \& Anjum (2013) farmers in rural areas are not able to patronize the benefits of commodity futures market. There are various reasons for the ineffective growth of commodity futures market in India. The major reasons are (Greenberg 2007) lack of knowledge or expertise, lack of quantity, inability to deliver, lack of good storage facilities, lack of financial support of liquidity and inability to maintain grades and standards of the commodity.

A study of the risk-management decisions of a risk-averse farmer is discussed in Broll et al (2013). Specifically they look at a farmer who wishes to sell commodities to two markets at two prices, however only one of the markets has access to the futures and is accessible by the farmer. They show, theoretically, using the concepts of strong correlation, that the farmer's optimal futures position hinges on the bivariate dependence of the random commodity prices in the two different markets. They further show that the farmer can find an optimal solution through over-hedging, full-hedging, or under-hedging strategies, depending on whether the two random prices are strongly positively correlated, uncorrelated, or negatively uncorrelated, respectively. Conroy \& Rendleman (1983) have proposed a theory of spot and forward commodity pricing with the assumption that future prices and future harvest of agricultural commodities are uncertain. The motivation being that a farmer's hedging decisions are influenced by expected output uncertainty, for this reason the spot and forward prices of agricultural commodities are also influenced by this uncertainty.

An integrated problem of procuring, processing and trading of commodities is proposed (Devalkar et al 2011). They propose to optimize the profits of an enterprise that procures a commodity (example, soya-bean) and processes it (say to produce soya-meal) and trades both the procured soya-bean and the value added soya-meal. While this formulation is applicable to an enterprise, it can be mapped to a farmer if one considers the procurement of seeds, fertilizers, 
pesticides (procuring) and the act of cultivating as processing and selling of the cultivated produce as trading. However, in practical reality, most Indian small farmers have absolutely no say what-so-ever in procurement of seeds, fertilizers and pesticides; the whole process of cultivation is uncertain and they have limited trading avenues. This warrants a formulation which allows him to maximize his profits, with very time limited storage facility.

We now formulate an optimization approach to enable a farmer to identify the market where we can sell with practical problems, namely, (a) he does not have much say in the procurement of seeds, fertilizers and pesticides which result in the procurement costs which being determined by the prevailing market conditions; (b) he does not have much facility to store his commodity so as to have a luxury of selling his commodities when he wants, especially the perishable commodity, (c) his liquidity status and education do not allow him to look for hedging.

\section{Problem formulation}

The formulation of the problem is along the lines of Saxena \& Kopparapu (2013) with the additional component of when to sell the commodity or produce. Let $L_{o}=\left(x_{o}, y_{o}\right)$ be the location of the farmer, where $x_{o}$ is the latitude and $y_{o}$ is the longitude. Let

$$
M=\left\{m_{1}, m_{2}, m_{3}, m_{4}, \cdots, m_{K}\right\}
$$

be a set of $K$ markets, where the farmer has an option of selling his produce $(p)$ and let the market $m_{i}$ be identified by the location $\left(x_{m i}, y_{m i}\right)$. Let $t_{n}$ denote $n$ days from today $\left(t_{0}\right.$ denoting today) and let $\boldsymbol{T}=\left\{t_{0}, t_{1}, \cdots, \cdots\right\}$.

Now the problem is to find a market $m_{k} \in M$ and $t_{n} \in \boldsymbol{T}$ such that the farmer maximizes his profit by selling his produce $p$ at $m_{k}$ on a date $t_{n}$. We now develop a cost function, which when minimized will result in the identification of the best market for the farmer to sell his produce and also suggest on which day he needs to sell.

The construction of a cost function depends on several factors which are discussed below. Geographical distance of the market from the location of the farmer is a crucial parameter as this determines not only the amount of time that is required to transport the produce but also bears an economic impact in terms of the transportation cost. Let

$$
d\left(I L, m_{k}\right)=R \cos ^{-1}\left(\cos \left(y-y_{m k}\right) \cos (x) \cos \left(x_{m k}\right)+\sin (x) \sin \left(x_{m k}\right)\right)
$$

be the distance between the farmers location $\mathbb{L}$ and the $k^{t h}$ market $m_{k}$. In (1), $R$ denotes the radius of the earth. The cost incurred by the farmer to transport his produce to the market $m_{k}$ from his location $\mathbb{L}$ is given by

$$
C_{k}^{\text {trptn }}=T_{c} \overbrace{\beta_{d c} d\left(\mathbb{I L}, m_{k}\right)}^{d_{p}\left(\mathbb{L}, m_{k}\right)},
$$

where $T_{c}$ is the transportation cost per unit distance and $\beta_{d c} \geq 1$ is the distance correction factor.

Note 1: Observe that $d\left(I L, m_{k}\right)$ computed using (1), gives the shortest distance between the locations $\mathbb{L}$ and $m_{k}$, however in reality, the actual distance, $d_{p}\left(\mathbb{L}, m_{k}\right)$, is determined by the paved path between $\mathbb{L}$ and $m_{k} . d_{p}\left(\mathbb{L}, m_{k}\right)$ can be obtained directly from Google distance matrix service API (Google 2013). 
We can rewrite (2) as

$$
C_{k}^{t r p t n}=T_{c} d_{p}\left(L, m_{k}\right)
$$

The actual time taken to move the produce ${ }^{1}$ from $I L$ to the market $m_{k}$ is another crucial parameter. If $T_{a c q}$ is the time required to acquire a vehicle for transporting the produce and $T_{\text {travel }}$ is the actual travel time required to cover the distance $\beta_{d c} d\left(\mathbb{L}, m_{k}\right)$, then the total time to transport the produce from $\mathbb{L}$ to the market is

$$
T_{k_{\text {time }}}=T_{\text {store }}+T_{\text {acq }}+T_{k_{\text {travel }}} .
$$

where $T_{\text {store }}$ is the time since the produce was harvested.

Note 2: $T_{a c q}=0$ for a farmer who owns a transport of his own (usually a tractor) and can use it as and when he wants to. In reality, most farmers depend on an external agency to transport their commodity and the availability of transport is difficult during post harvesting season when all the farmers are in need of transport to move their produce.

Note that the transportation time is more crucial for perishable produce. If $\gamma_{p}$ is the perishability index of the produce $p$ such that $\gamma_{p} \in[0, \infty[$. Then the cost associated with the time parameter is

$$
C_{k}^{\text {time }}=T_{k_{\text {time }}}^{\gamma_{p}}=\left(T_{\text {store }}+T_{\text {acq }}+T_{k_{\text {travel }}}\right)^{\gamma_{p}} .
$$

Note 3: The perishability index $\gamma_{p}$ is small for a non-perishable produce and takes a higher value if the produce is perishable, which supports the fact that the time taken for transportation is not a very important parameter for commodities that are not perishable. For $\gamma_{p}=0, C_{k}^{\text {time }}=1$.

Note 4: The perishability index $\gamma_{p}$ in our formulation is considered to effect the cost as a power of the total time in (4). This is based loosely on (Mathew 2013) and the observation (figure 2) that the degradation of a commodity is not linear.

The overall profit made by the farmer by selling his produce is an important factor that dictates when to sell $\left(t_{n}\right)$ and in which market $\left(m_{k}\right)$ to sell. Let $C_{o}\left(m_{k}, p, g, t_{n}\right)$ be the purchasing price of the produce $p$ of grade $g$ in a market $m_{k}$ on day $n$; today if $n=0$ denoted by $t_{0}$. Suppose $q$ is the quantity of commodity that the farmer has to sell and let $C(p, g)$ be the production cost of the produce $p$ of grade $g$. Then, the profit made by the farmer is

$$
C_{k, t_{n}}^{\text {profit }}=q\left(C_{o}\left(m_{k}, p, g, t_{n}\right)-C(p, g)\right) .
$$

Note 5: Seller is the farmer and the buyer is the trader.

However, the quantity of a produce reduces due to weight loss, with time especially in ambient conditions. The weight loss is significant, for example there is a $50 \%$ weight loss in case of carrot and $28 \%$ for green onion over a period of 7 days (Dadhich et al 2008). This has to be accounted

\footnotetext{
${ }^{1}$ We use produce and commodity interchangeably in this paper.
} 
for when we compute the quantity, $q$, of a produce. If $q^{\prime}$ is the weight of the produce at the time of harvesting, then the actual weight of the produce, $p$ at the time of selling is given by

$$
q=\Omega\left(p,\left(T_{\text {store }}+\left|t_{n}\right|\right)\right) q^{\prime},
$$

where $\Omega(\bullet)$ can take a value in the range $[0,1]$ and depends on the type of the produce, the storage time $\left(T_{\text {store }}\right)$ and the day $\left(\left|t_{n}\right|=n\right)$ on which the farmer plans to sell the produce. In all our experiments, we assume that there is no significant change in weight of the produce, namely $\Omega(\bullet)=1$. This makes sense in the light that most farmers have no special facility to store their produce.

It should be noted that the perception of grade of a produce $(p)$ by the seller and the buyer are often different; as expected, the seller (in this case the farmer) has an opinion of the grade being better than what it actually is and the buyer has an opinion of the grade of the produce being lesser than what it actually is. Figure 1 captures the perception difference between the framer and the trader; clearly the variation in the perception is maximum in the medium grade range of the produce. This has to be accounted for in (5). If $g$ is the perceived grade of the produce by the farmer then the grade perceived by the trader is

$$
g^{\prime}=\tau g,
$$

where, $\tau$, the perception ratio can be computed from figure 1 in the following way. If the perceived grade by the farmer, say the point represented by the open circle on the dotted line $g=k$, then the corresponding grade perceived by the trader is (denoted by the by the filled circle in figure 1 ) is $g^{\prime}=l$; in this case the perception ratio is

$$
\tau=\frac{l}{k}
$$

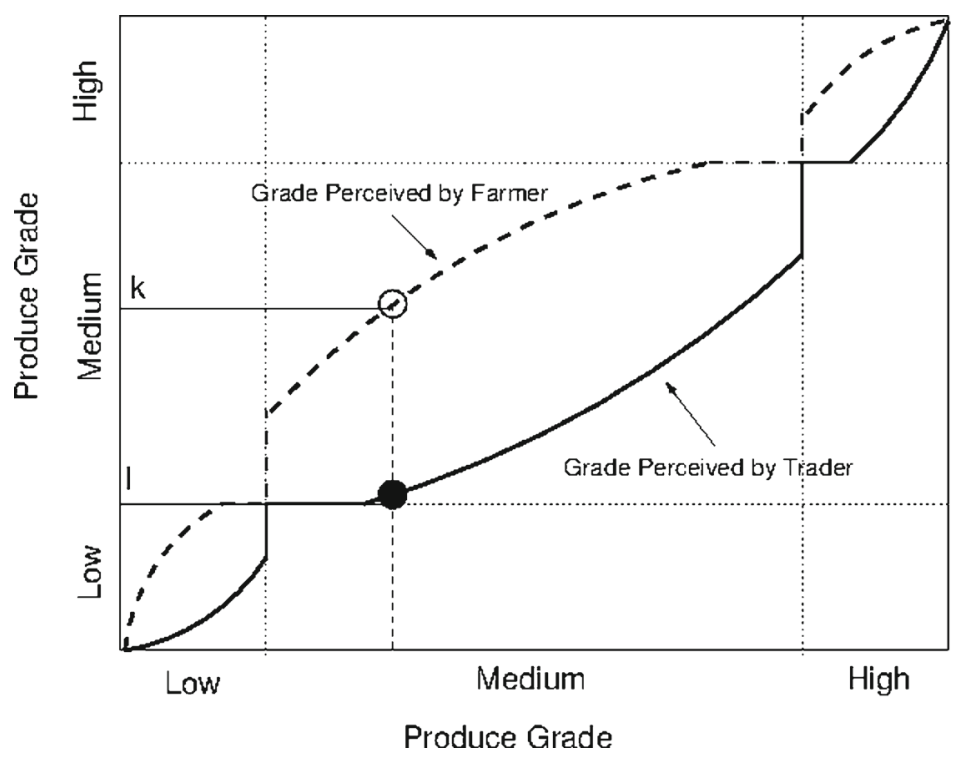

Figure 1. Difference in grade perception between the farmer and the purchaser. 
Note 6: $\tau$ take a value closer to 1 when the produce quality is either low or high (smaller variation in perception of the quality of the produce) and take a value far from 1 for produce that is of medium grade (larger variation in perception of the quality of produce between the seller and the buyer).

Further, there is a degradation of the grade of the produce with time as seen in figure 2 (Greenstone 2013) which is different for perishable items (example: fruits and vegetables) and durable (example: cereals and pulses). The factor $\mu$ can be computed from figure 2 and depends on $T_{\text {store }}$ and $\left|t_{n}\right|$. So (6) becomes

$$
g^{\prime \prime}=\mu g^{\prime}=\mu \tau g
$$

Subsequently, (5) can be written as

$$
C_{k, t_{n}}^{\text {profit }}=q\left(C_{o}\left(m_{k}, p, g^{\prime \prime}, t_{n}\right)-C(p, g)\right) .
$$

Note that the cost function to determine the best time and the best market for the farmer to sell should minimize the cost of transportation $C_{k}^{\text {trptn }}$, minimize the time for transportation, namely, minimize $C_{k}^{\text {time }}$ and simultaneously maximize the profit made by the farmer, namely, maximize $C_{k, t_{n}}^{\text {profit }}$. Let $C_{k, t_{n}}$ be the profit associated with selling a produce $p$ at the market $m_{k}$ on day $t_{n}$ ( $t_{0}$ is today),

$$
C_{k, t_{n}}=-\alpha_{1} C_{k}^{\text {trptn }}-\alpha_{2} C_{k}^{\text {time }}+\alpha_{3} C_{k, t_{n}}^{\text {profit }},
$$

where, $\alpha_{1}, \alpha_{2}, \alpha_{3}$ are constants. While $\alpha_{1}$ and $\alpha_{3}$ are dimensionless, $\alpha_{2}$ has the dimension of cost per unit time. Note that $C_{k}^{t r p t n}$ and $C_{k}^{\text {time }}$ are independent of $t_{n}$. Now the problem reduces

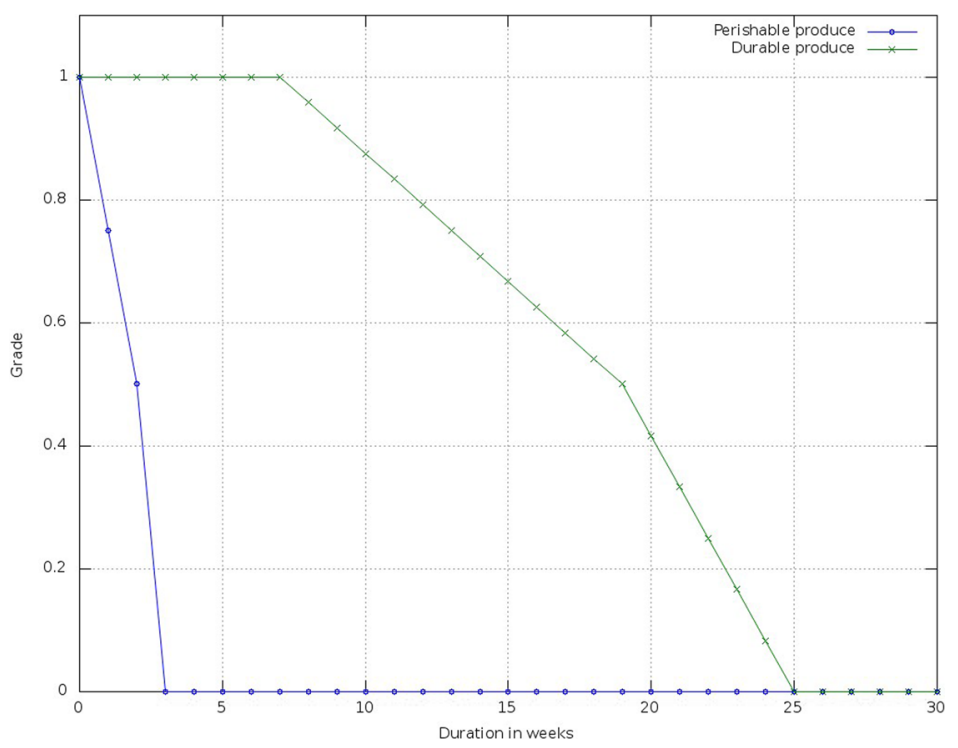

Figure 2. Detoriation of grade of commodity versus time (Greenstone 2013). 
to that of finding a market $m_{k}(\in M)$ and an appropriate time $t_{n}(\in \boldsymbol{T})$ to sell such that $C_{k, t_{n}}$ is maximum, namely, $\max _{m_{k}, t_{n}}\left\{C_{k, t_{n}}\right\}$ or,

$$
\max _{m_{k}, t_{n}}\left\{-\alpha_{1} C_{k}^{\text {trptn }}-\alpha_{2} C_{k}^{\text {time }}+\alpha_{3} C_{k, t_{n}}^{\text {profit }}\right\} .
$$

Or

$$
\max _{m_{k}, t_{n}}\left\{\begin{array}{l}
-\alpha_{1}\left(T_{c} \beta_{d c} d\left(\mathbb{L}, m_{k}\right)\right) \\
-\alpha_{2}\left(T_{\text {store }}+T_{a c q}+\left(T_{\text {travel }}\right)^{\gamma_{p}}\right) \\
+\alpha_{3}\left\{q\left(C_{o}\left(m_{k}, p, g^{\prime \prime}, t_{n}\right)-C(p, g)\right)\right\}
\end{array}\right\} .
$$

Now the problem of identifying the best market to sell and when to sell can be stated as

Given (a) location of the farmer $\mathbb{I},(b)$ information about the quantity $(q)$ of the produce $p,(c)$ the cost of production $C_{p}(p, g),(d)$ perishability index $\left(\gamma_{p}\right)$ of the produce, $(e)$ the geo-location of the markets $M$ and $(f)$ the selling price of the $p$, namely $C_{o}\left(m_{k}, p, g^{\prime \prime}, t_{n}\right)$. Find the market $\left(m_{k} \in M\right)$ where and the time $\left(t_{n} \in \boldsymbol{T}\right)$ when the farmer should sell his produce to maximize his gains, namely solve (9).

Note that in (9) the selling price of the produce $p$ of grade $g^{\prime \prime}$ in the market $m_{k}$ is known until today, namely $C_{o}\left(m_{k}, p, g^{\prime \prime}, t_{n \leq 0}\right)$ is known, however $C_{o}\left(m_{k}, p, g^{\prime \prime}, t_{n}\right)$ for $n>0$ is into the future and is not apriori known. This has to be estimated.

\subsection{Estimating $C_{o}\left(\cdots, t_{n>0}\right)$}

There are several factors that contribute to the determination of the selling price of a produce into the future, in this paper, we estimate the price of the commodity using only the past selling data of that commodity. Namely,

$$
\hat{C}_{o}\left(\cdots, t_{k}\right)=\mathbb{I}\left(C_{o}\left(\cdots, t_{k-1}\right), C_{o}\left(\cdots, t_{k-2}\right), \cdots, C_{o}\left(\cdots, t_{k-Q}\right)\right),
$$

where $\hat{C}_{o}\left(\cdots, t_{k}\right)$ is the estimate of the selling price on $t_{k}$ and $\left\{C_{o}\left(\cdots, t_{k-i}\right)\right\}_{i=1}^{Q}$ are the past selling prices of the same commodity. $\mathbb{F}$ is a function that identifies the best estimate, namely, $\hat{C}_{o}\left(\cdots, t_{k}\right)$. In this paper, we use linear regression (Makhoul 1975) to estimate $\hat{C}_{o}\left(\cdots, t_{k}\right)$.

In the linear prediction (LP) model, the selling price of the commodity is estimated as a linear combination of the past known values of the selling price, namely

$$
\hat{C}_{o}\left(\cdots, t_{k}\right)=\sum_{i=1}^{Q} \omega_{i} C_{o}\left(\cdots, t_{k-i}\right),
$$

where, $\hat{C}_{o}\left(\cdots, t_{k}\right)$ is the estimate, $Q$ is the order of the LP model and $\left\{\omega_{i}\right\}_{i=1}^{Q}$ are the predictor coefficients. The idea is to identify $\left\{\omega_{i}\right\}_{i=1}^{Q}$ in (10) such that

$$
\sum_{k}\left(\hat{C}_{o}\left(\cdots, t_{k}\right)-C_{o}\left(\cdots, t_{k}\right)\right)^{2}
$$

is minimized. Having estimated $C_{o}\left(m_{k}, p, g^{\prime \prime}, t_{n}\right)$ for $n>0$, we now have all the information required to solve (9). 


\section{Results and discussion}

We first describe the acquisition of real data (TCS 2014) for the purposes of demonstrating the usefulness of the formulated scheme to identify the best market and best time for the farmer to sell his produce to maximize his profits. The first part of the experimental results are aimed at identifying the goodness of LP model in estimating the commodity price at a future date; and the second part of the experimental results is directed towards verifying the validity and appropriateness of the suggested formulation to assist a farmer to identify the market and the day-to-sell to maximize his profits.

\subsection{Data acquisition}

We sourced actual data from the web to construct our experimental data set (TCS 2014). We identified all the agricultural markets and also gathered the list of agricultural produce that is cultivated in the state of Maharastra in India. Figure 3 shows the location of the markets in latitude, longitude measured as distance in kilometers and table 1 shows a list of top few agricultural produce that are cultivated in the state of Maharastra, India (Manase.Org 2013). However, the perishability index in table 1 is chosen to reflect the life time of the agricultural produce and is not exact. For the first produce in table 1, namely Cotton, we sourced the market price of the commodity (Agmarknet 2013). For the purpose of analysis, we considered details (location of the farmer, the cost of cultivation and the quantity of produce cultivated) associated with a farmer who was registered with mKRISHI (TCS 2013), which is a personalized mobile based agro advisory system that connects the farmers to agricultural experts. Using Google distance matrix service API (Google 2013) we computed the road distance and the travel time between two locations; this formed our complete dataset (please see (TCS 2014)). In all, there are 228 trading markets in Maharastra of which only 34 traded in cotton.

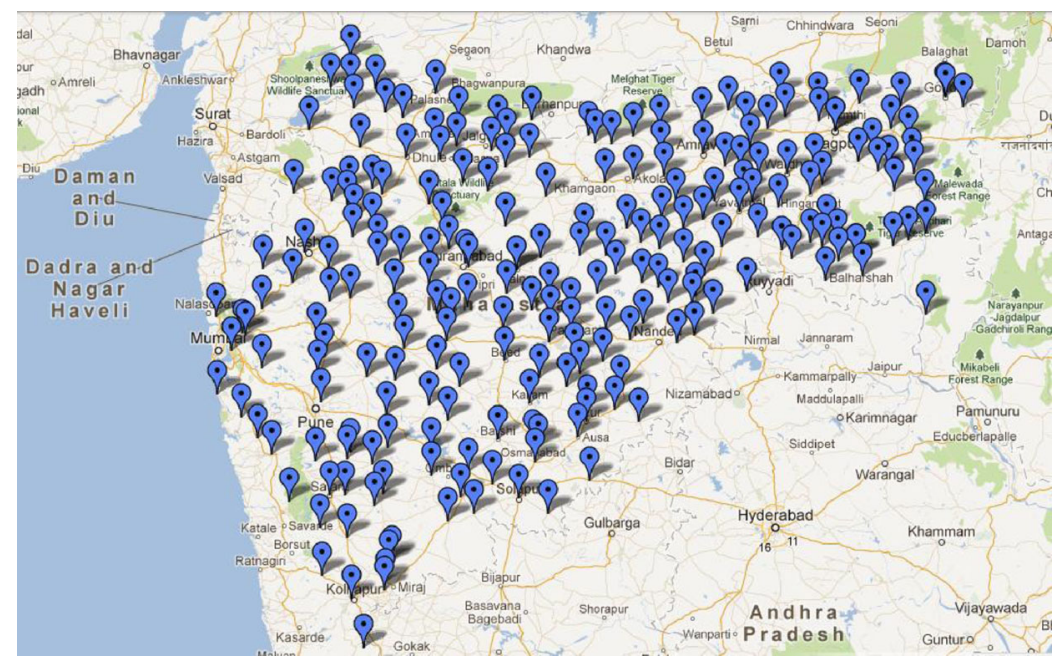

Figure 3. Trading markets (TCS 2014) in the state of Maharastra. There are a total of 228 trading markets. 
Table 1. Commodities cultivated in Maharastra (Manase.Org 2013).

\begin{tabular}{llcc}
\hline SNo & Commodity & $\begin{array}{c}\text { Area cultivated } \\
\text { (in lakh hectares) }\end{array}$ & $\begin{array}{c}\text { Perishability } \\
\text { Index }(\gamma)\end{array}$ \\
\hline 1 & Cotton & $30-35$ & 0.01 \\
2 & Total Pulses & $25-30$ & 0.1 \\
3 & Spiked Millet & $15-20$ & 0.1 \\
4 & Rice & $12-15$ & 0.1 \\
\hline
\end{tabular}

\subsection{Case study}

In this case study, we consider that the farmer (shown in figure 4) located in northern Maharastra who cultivates $(q=) 60$ quintal of $(p=)$ Cotton, and the cost of production $(C($ Cotton,,$)=)$ is 1500 rupees per quintal. Figure 4 also shows the plot of markets that trade only in Cotton along with the spatial location of the farmer (red open circle). Through out this study we have considered only the 34 markets that traded in cotton where the farmer could sell his produce.

Our initial task was to determine the ability of the LP model to estimate the commodity price, namely, determine $C_{o}\left(\cdots, t_{n>0}\right)$ as mentioned in section 3.1. We choose one of the 34 markets that traded in Cotton. For the purposes of estimating $\hat{C}_{o}\left(\cdots, t_{k}\right)$ we collected 24 months of selling price data from (Agmarknet 2013) and used it to find $\left\{\omega_{i}\right\}_{i=1}^{Q}$ for $Q=3,7,11$. There were a total of 696 selling price data points. We used $80 \%$ of the data (556 data points) to compute the LP coefficients $\left(\left\{\omega_{i}\right\}\right)$ using the well known Burg method. The computed LPC for $Q=3,7,11$ are given in table 2 .

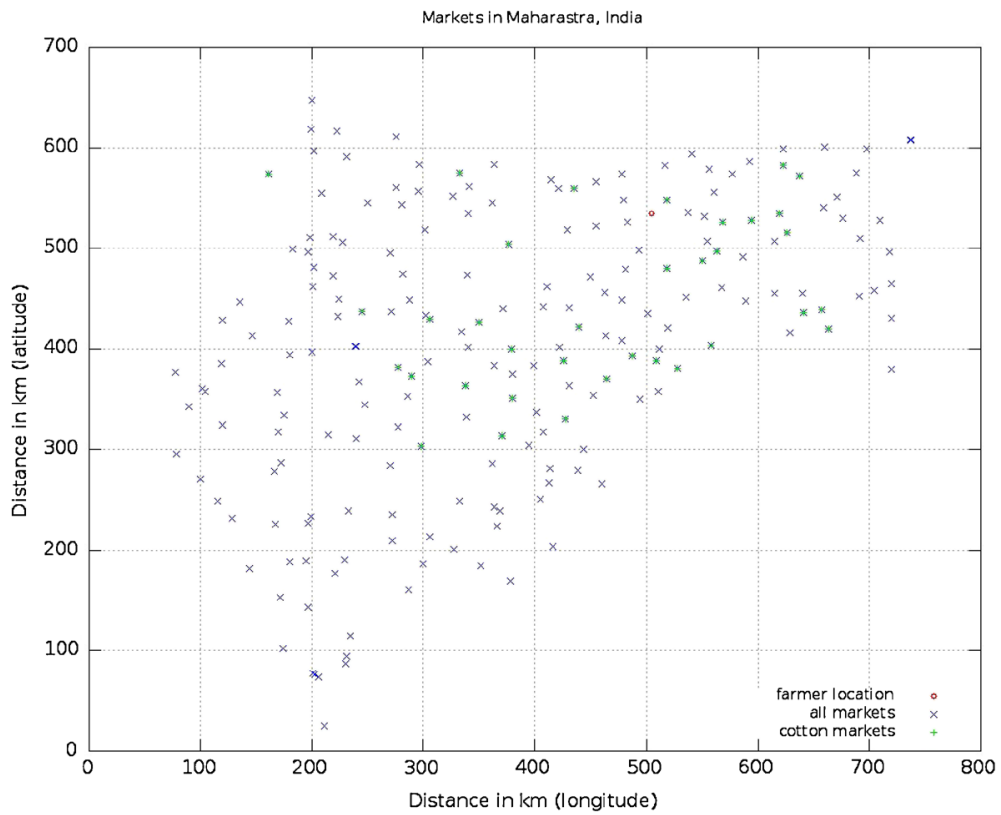

Figure 4. Data showing the location of the farmer (represented by "o") along with the markets which trade in Cotton (shown by "*"), "x" represents all the markets in Maharastra. 
Table 2. LPC for $Q=3,7,11$.

\begin{tabular}{cl}
\hline$Q$ & $\left\{\omega_{i}\right\}_{i=1}^{Q}$ \\
\hline 3 & $-0.918-0.0326-0.0350$ \\
7 & $-0.917-.0336-0.034-0.0060 .0310 .0050-0.027$ \\
11 & $-0.918-0.034-0.0390 .0010 .030-0.005-0.0980 .045-0.0050 .106-0.067$ \\
\hline
\end{tabular}

The computed $\left\{\omega_{i}\right\}$ was used to estimate the selling price for the rest of the $20 \%$ (140 points) of the data. The performance of the LP for different values of $Q$ is shown in figure 5. In each of the plot, the original selling price is represented as " $x$ " in blue. The first $80 \%$ of the data was used to compute LPC while the last $20 \%$ was used as the test data. The line plot in red shows the estimate using the LPC on the train data itself while the last 140 points represented by "+" in green shows the performance of the prediction on the test data. We computed the normalized root mean square error (normalized RMSE) to determine the performance of the LPC order in predicting the commodity selling price. If $\left\{\hat{x}_{i}\right\}_{i=1}^{N}$ is the estimate of $N$ original data points $\{x\}_{i=1}^{N}$, then normalized RMSE is defined as

$$
\mathrm{n}-\mathrm{RMSE}=\frac{\sqrt{\sum_{i=1}^{N} \frac{(\hat{x}-x)^{2}}{N}}}{\left(\hat{x}_{\max }-\hat{x}_{\min }\right)} .
$$
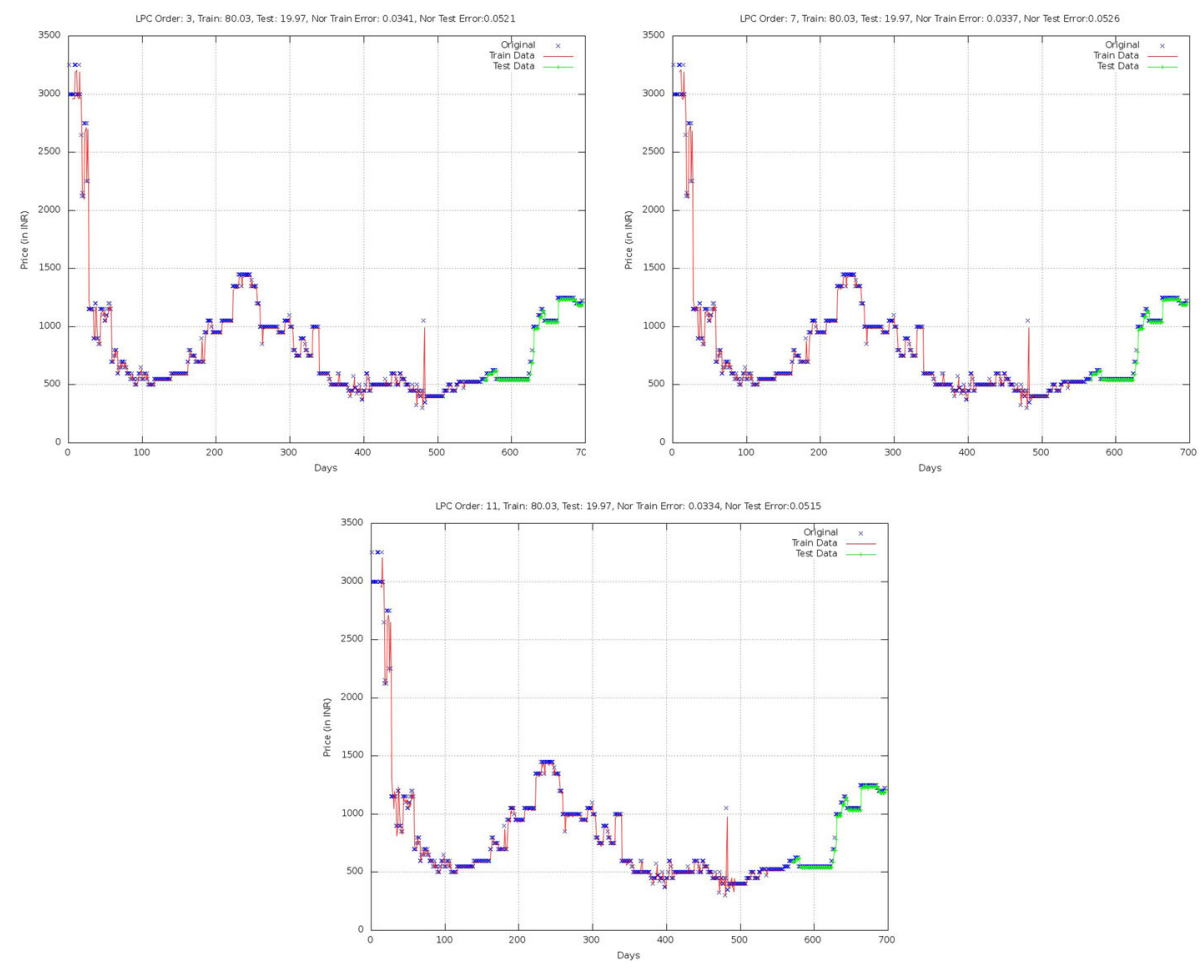

Figure 5. LPC using $Q=3,7,11$. The order does not effect the estimation of commodity price, namely, $C_{o}\left(\cdots, t_{n>0}\right)$. 
Table 3. Normalized root mean squared error for different $Q$.

\begin{tabular}{lcc}
\hline$Q$ & n-RMSE (train) & n-RMSE (test) \\
\hline 3 & 0.0341 & 0.0521 \\
7 & 0.0337 & 0.0526 \\
11 & 0.0334 & 0.0515 \\
\hline
\end{tabular}

The n-RMSE computed for both the train data set (80\%) and the test data set (20\%) is similar irrespective of the order (see table 3). Clearly, all orders $(Q)$ of LPC seem to be able to model the selling price of the commodity equally well with low n-RMSE. We conclude that LP can indeed model effectively the selling price of a commodity and hence can be used to estimate the selling price of a commodity for a future date.

As reported in our earlier work (Saxena \& Kopparapu 2013) we determined only the best market to sell (and not the time to sell) the commodity, namely, $t_{n=0}$ in (9). It was shown (Saxena \& Kopparapu 2013) that it is indeed not possible to determine the best sell market by considering either the cost of transportation or the travel time or the market buying the produce alone. We further showed that solving (9) for $t_{n=0}$ was able to identify the best market to sell the commodity with best returns.

This case study, extends our earlier reported results, to identify not only the best market to sell, but also to determine the best time to sell. In what follows we demonstrate the effectiveness of the cost function in determining the best where and when to sell market, clearly the best where and when to sell market is dependent on several parameters, ranging from the cost of production, the distance of the market, the perishability index of the produce, etc. Here, we have considered the option of the best sell market in terms of not only the market but also the day on which to sell, ${ }^{2}$ namely $t_{0 \leq n \leq 7}$. Observe that the first two components in (9) are independent of $t_{n}$ (see figure 6), while the third component depends on $t_{n}$. Figure 7 shows the commodity price in the 34 markets trading in Cotton for $t_{n=1, \cdots, 7}$. For the purposes of experimentation, we took the actual selling price of cotton that was reported in Agmarknet (2013). Observe that there are several days on which there was no trade in cotton, this is depicted by selling price represented by 0 . Figure 6 also depicts some of the closest markets in terms of distance and time, these have been represented by a "+" (in blue). Note that the set of markets which are closest to the farmer in terms of distance (MARKET : 3, 27, 29, 30, 34 in figure 6(a)) is not the same as the markets that are closest in terms of time taken to travel (MARKET: 3, 22, 27, 29, 30 in figure 6(b)). We first normalized the data shown in figures 6 and 7 individually ${ }^{3}$ so that the minimum cost is represented by the value 0 and the maximum cost is represented by 1 . For example, if $\mathcal{C}=\left\{C_{1}, C_{2}, \cdots C_{n}\right\}$ are the costs then the normalized cost $C^{\prime}$ was computed as

$$
C_{i}^{\prime}=\frac{C_{i}-C_{\min }}{C_{\max }-C_{\min }}
$$

where $C_{\min }=\min \{\mathcal{C}\}$ and $C_{\max }=\max \{\mathcal{C}\}$.

\footnotetext{
${ }^{2}$ We restricted our analysis to a seven day look forward period considering the practicality of access to storage for longer period for a typical farmer.

${ }^{3}$ The range of the $y$-axis in figures 6 and 7 after normalization is between 0 and 1 .
} 


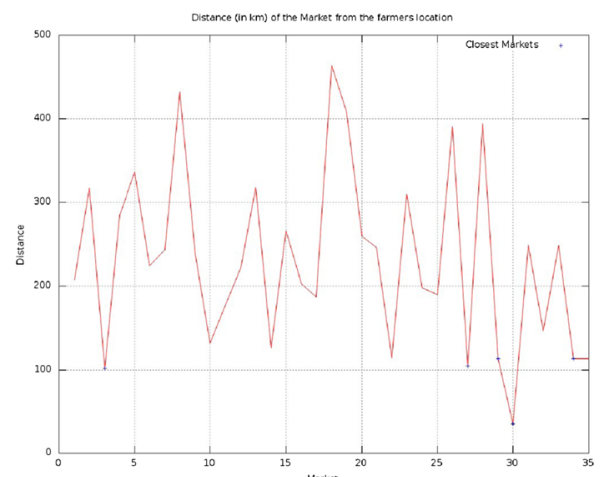

(a)

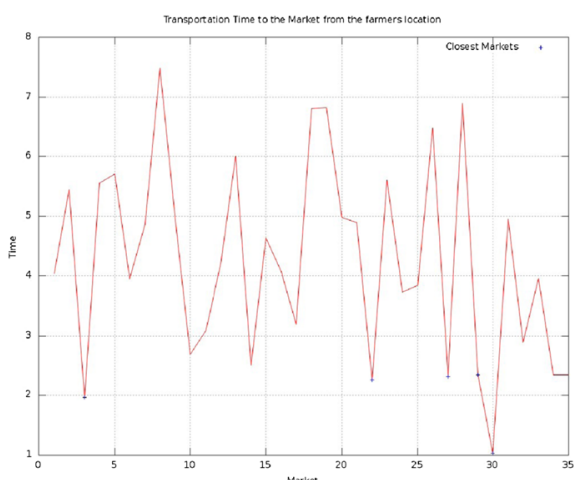

(b)

Figure 6. Distance of the market and the time to reach the market are independent of $t_{n}$. The top five closest market in terms of distance and time are depicted by a blue "+".

Note 7: The normalization of the data allows the use of $\alpha_{1}=\alpha_{2}=\alpha_{3}=1 / 3$ in (9).

Using the normalized data (figures 6 and 7 depict the data before normalization) we computed $C_{k, t_{n}}$ (see (8)) for $k=1, \cdots, 34$ and for $t_{n=1, \cdots, 7}$, a total of $34 \times 7 C_{k, t_{n}}$ 's. Figure 8 depicts the
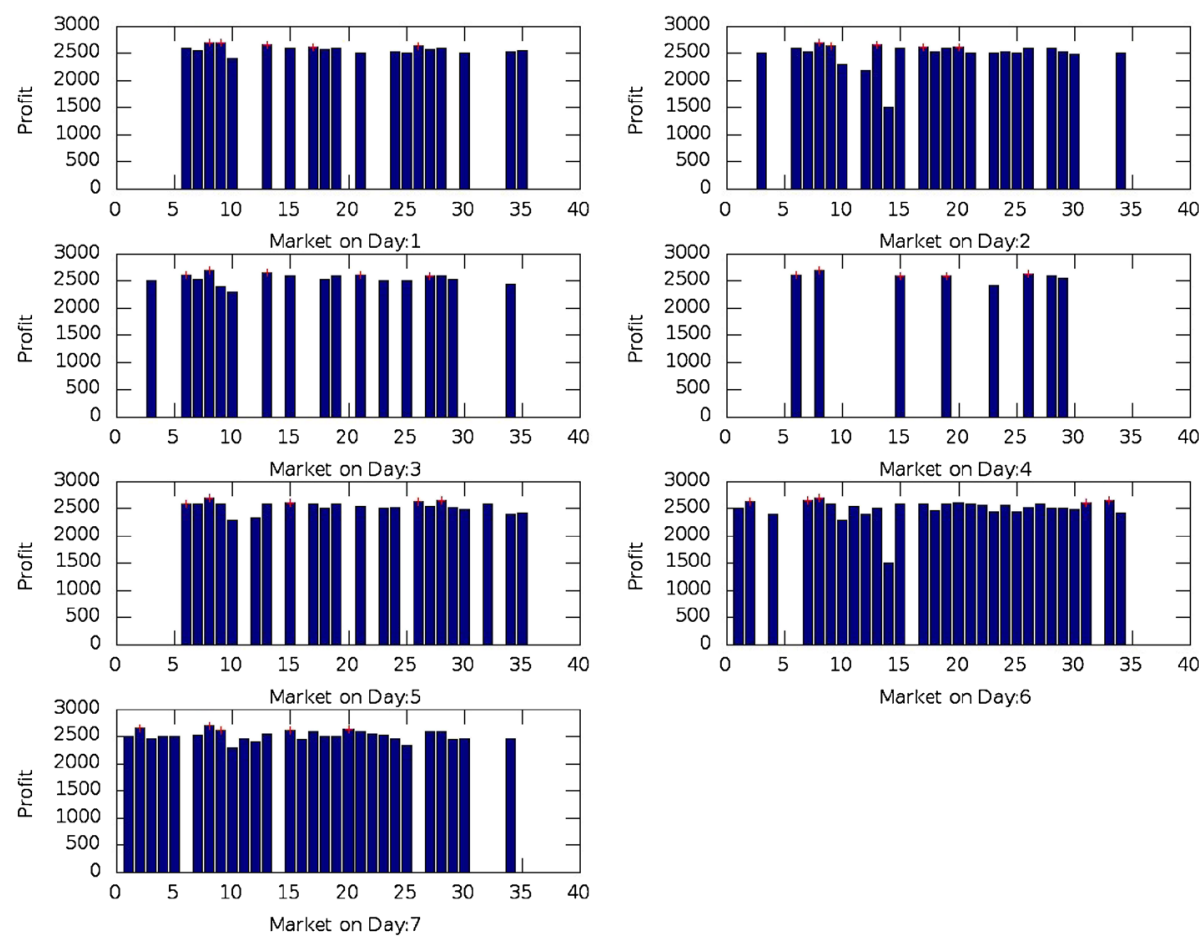

Figure 7. The selling price of commodity in the market varies with the day. For each day the market with the maximum selling price is depicted by red "+". 


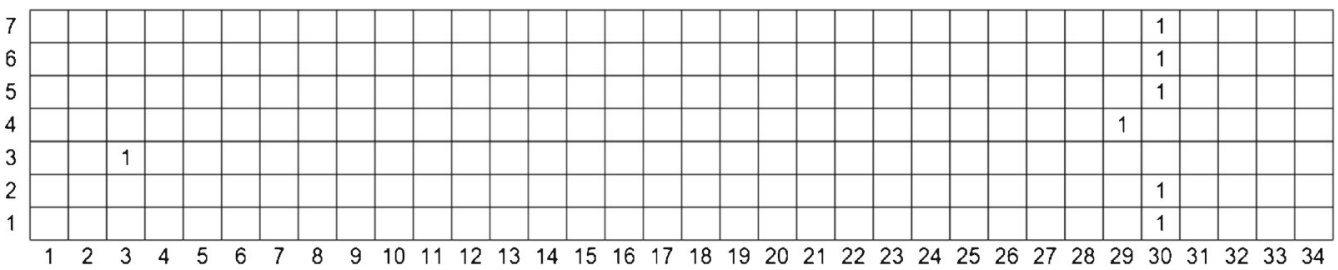

Figure 8. Where to sell and when to sell (computed using algorithm 1). Equal weightage to all the three factors. The $x$-axis is the market and $y$-axis represents $t_{n}$.

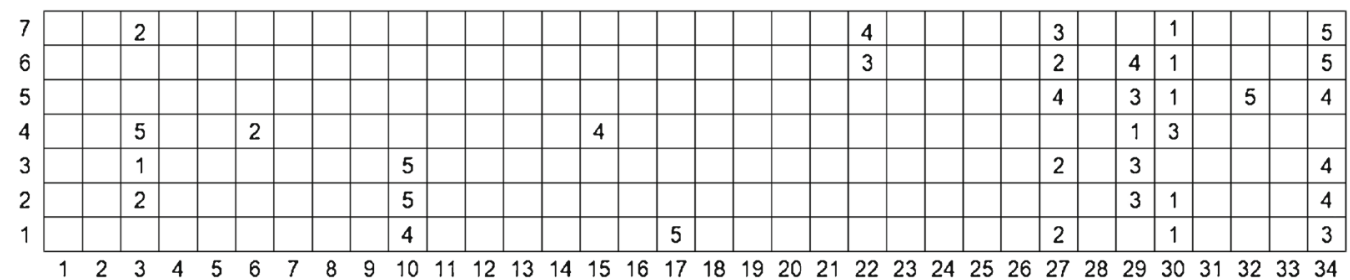

Figure 9. Where to sell and when to sell (top 5 markets).

Table 4. Top 5 market (figure 9) with the $C_{k, t_{n}}$ values.

\begin{tabular}{cccccc}
\hline$t_{n}$ & $\operatorname{Market}\left(C_{k, t_{n}}\right)$ & $\operatorname{Market}\left(C_{k, t_{n}}\right)$ & $\operatorname{Market}\left(C_{k, t_{n}}\right)$ & $\operatorname{Market}\left(C_{k, t_{n}}\right)$ & $\operatorname{Market}\left(C_{k, t_{n}}\right)$ \\
\hline 1 & $30(0.3155)$ & $27(0.2007)$ & $34(0.1887)$ & $10(0.1467)$ & $17(0.0963)$ \\
2 & $30(0.3139)$ & $3(0.2150)$ & $29(0.1890)$ & $34(0.1863)$ & $10(0.1389)$ \\
3 & $3(0.2150)$ & $27(0.2029)$ & $29(0.1890)$ & $34(0.1824)$ & $10(0.1389)$ \\
4 & $29(0.1902)$ & $6(0.0276)$ & $30(0.0000)$ & $15(-0.0399)$ & $3(-0.0992)$ \\
5 & $30(0.3127)$ & $27(0.1995)$ & $29(0.1882)$ & $34(0.1792)$ & $32(0.1405)$ \\
6 & $30(0.3135)$ & $27(0.2029)$ & $22(0.1968)$ & $29(0.1871)$ & $34(0.1801)$ \\
7 & $30(0.3116)$ & $3(0.2131)$ & $27(0.2026)$ & $22(0.1940)$ & $34(0.1841)$ \\
\hline
\end{tabular}

best market to sell on any given day. The $x$-axis represents the 34 markets that trade in Cotton and $y$-axis represents $t_{n=1, \cdots, 7}$ the day. From figure 8 we find that the best market to sell is MARKET 9 on $t_{1}$ and it is MARKET 8 for $t_{n=2,3,4,5,6,7}$ (see Algorithm 1).

To understand if there was variability at all in terms of choice of market, we computed the best 5 markets for $t_{n=1, \cdots, 7}$. This is shown in figure 9. Each row, depicts the day, has a rank from 1 to 5 associated with the top 5 best markets to sell. For example, for $t_{n=1}$, the farmer has maximum gain by selling in market MARKET 9 (computed using (9)) followed by MARKET 8, MARKET 13, MARKET 26 and MARKET 17, while if he were to sell on $t_{n=7}$ then his order of choice of markets to sell would be MARKet 8, Market 2, Market 20, MARKet 15, and Market 9. Clearly, there is a variation in the best sell market depending on the day the farmer wishes to sell his produce to maximize his gains. Table 4 shows the best 5 markets to sell with $C_{k, t_{n}}$ values computed using (9). 


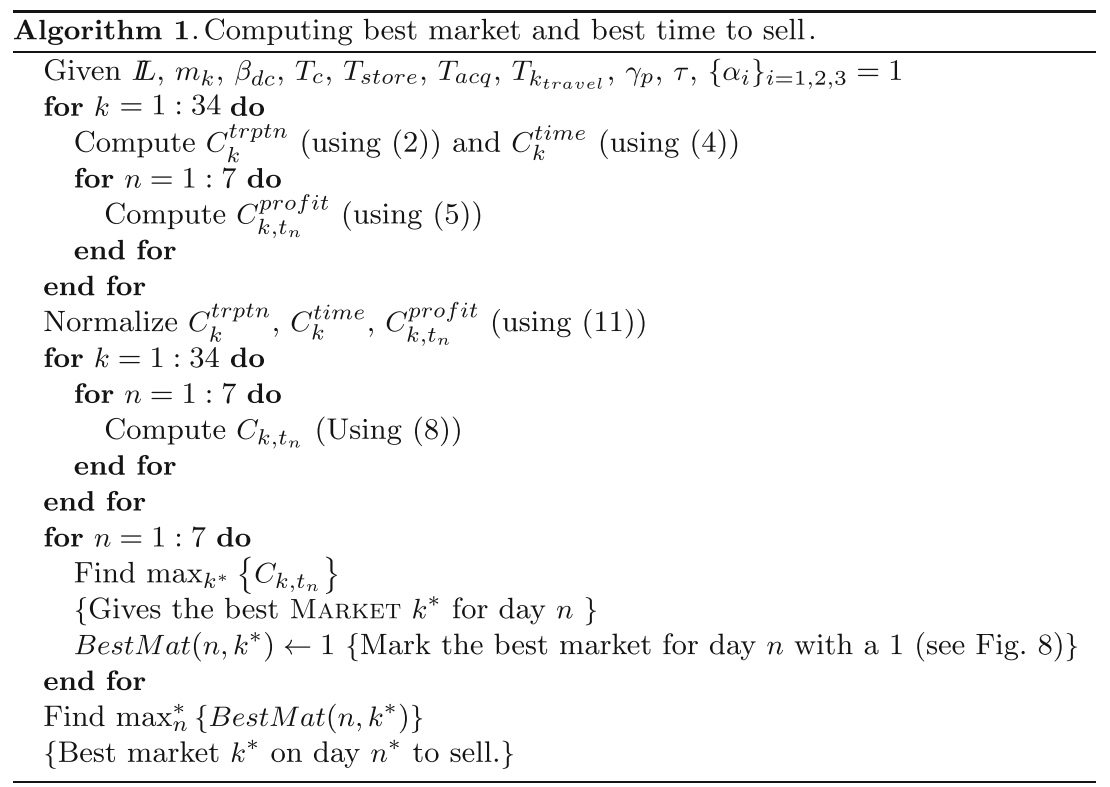

\section{Conclusions}

Information technology has been used effectively in the rural settings to assist farmers in giving information related to agricultural practices and also put them in touch with experts. However, to the best of our knowledge it lacks one important aspect, namely that of identifying a procurement market where the farmer can sell his produce to maximize his profits. The farmer now has an option of not only selling his produce in a market of his choice, but also can decide when to sell with the main goal of enhancing his profits. In this paper, we formulated the problem of identifying the best where and when to sell market as an optimization problem whose solution determines not only the market in which he should sell his produce but also in terms of when to sell. We sourced the web to construct a real data set (TCS 2014) which was then used (i) to establish that the selling price of the produce can be estimated based on the available past selling prices of the commodity using linear prediction (LP) and (ii) to determine the best where and when to sell market, to enable the farmers to maximize their profits. Experimental results have shown that the proposed cost optimization formulation could identify the best where and when to sell market by optimizing over space (market), time (day to sell) and other agricultural parameters.

\section{References}

Agmarknet. Agmarknet 2013 agmarknet.nic.in/

Ahmed Imran and Sunil Kumar Kopparapu 2011 Building a natural language Hindi speech interface to access market information. In The Third National Conference on Computer Vision, Pattern Recognition, Image Processing and Graphics

Donald E Greenberg 2007 Price risk management by indian farmers - hedging wheat in haryana state. http://globalfoodchainpartnerships.org/india/Presentations/3rd\%20International\%20Conference.pdf

Greenstone. Greenstone 2013 http://www.greenstone.org/greenstone3/ 
Google. Distance matrix API 2013 https://developers.google.com/maps/documentation/javascript/ distancematrix

Harwinder Pal Kaur and Bimal Anjum 2013 Agricultural commodity futures in India - a literature review. GALAXY Int. Interdiscipl. Res. J. 1(1). http://internationaljournals.co.in/pdf/GIIRJ/2013/November/5. pdf

John Mathew R 2013 Perishable inventory model having mixture of weibull lifetime and demand as function of both selling price and time. Int. J. Sci. Res. Publ., 3(7) http://www.ijsrp.org/research-paper-0713/ ijsrp-p1955.pdf

Makhoul J 1975 Linear prediction: A tutorial review. Proceedings of the IEEE, 63(4): 561-580. ISSN 0018-9219. doi: 10.1109/PROC.1975.9792

Manase.Org. Crops - area and production 2013 https://www.manase.org/en/maharashtra.php?mid=68\& smid $=21 \&$ id $=973$

Robert M. Conroy and Richard J. Rendleman 1983 Pricing commodities when both price and output are uncertain. J. Futures Markets, 3(4): 439-450 ISSN 1096-9934. doi: 10.1002/fut.3990030409

TCS 2013 mKRISHI: Agro Advisory Platform. http://www.tcs.com/offerings/technology-products/ mKRISHI/Pages/default.aspx

TCS. Dataset 2014 https://sites.google.com/site/awazyp/data-bsm

Sripad K. Devalkar, Ravi Anupindi and Amitabh Sinha 2011 Integrated optimization of procurement, processing, and trade of commodities. Operations Res., 59(6): 1369-1381 doi: 10.1287/opre.1110.0959. http://pubsonline.informs.org/doi/abs/10.1287/opre.1110.0959

Sushmita Mukherjee Dadhich, Hemant Dadhich and RadhaCharan Verma 2008 Comparative study on storage of fruits and vegetables in evaporative cool chamber and in ambient. Int. J. Food Eng., 4(1)

Udo Broll, Peter Welzel and Kit Pong Wong 2013 Price risk and risk management in agriculture. Contemporary Economics, 7(2) http://EconPapers.repec.org/RePEc:wyz:journl:id:280

Vikram Saxena and Sunil Kumar Kopparapu 2013 An optimization approach to identify the best sell market. In David Al-Dabass, Alessandra Orsoni, Jasmy Yunus, Richard Cant, and Zuwairie Ibrahim, editors, UKSim, pages 177-181. IEEE. ISBN 978-1-4673-6421-8 